\title{
ANALYSIS OF RADIATION-DRIVEN EXPLOSIVE FLYERS
}

\author{
R. J. Lawrence, J. R. Asay, T. G. Trucano, and C. A. Hall \\ Sandia National Laboratories," Albüquerque, NM 87185
}

RECEIVED

AUG 1 \1999

\begin{abstract}
There is great interest in being able to use the $x$-ray output from a Z-pinch for equation of state measurements at extreme conditions. However, the direct x-ray output from the pinch produces a very sharp and rapidly attenuating pressure pulse in target materials. To obtain high quality measurements with this source, a mechanism for generating non-attenuating waves is needed. One possibility involves using the $x$-ray source to throw a near-normal density intermediate driver at the target, a situation similar to more conventional configurations. To scope out preliminary design parameters, we used the ALEGRA code to simulate a number of different possibilities involving the driver and the gap between it and the target. We used a somewhat idealized radiation source-a main $\mathrm{x}$-ray pulse $30 \mathrm{~ns}$ long at its base and peaking at a blackbody temperature of $100 \mathrm{eV}$. The calculations suggest that a 100-micron aluminum driver with a 90-micron gap will yield a 15-ns-wide nonattenuating pulse with an amplitude of over $250 \mathrm{GPa}$.
\end{abstract} OSTI

\section{INTRODUCTION}

The $\mathrm{Z}$ machine at Sandia National Laboratories uses fast $Z$ pinches to provide large quantities of near Planckian soft $\mathrm{x}$-ray energy, 1,2 which we would like to use for high-pressure equation of state studies. Unfortunately, the pressure and shock waves generated by direct deposition of this energy source are very narrow and sharp, and attenuate rapidly as they propagate through typical target materials. For high-quality equation of state measurements we would like these pulses to be non-attenuating. There are probably many ways to achieve this goal, for example interposing a lowdensity foam layer between the source and the target, but here we will examine a somewhat different approach. If we use the high-energy radiation pulse to ablatively or "explosively" drive an intermediate layer or flyer, the proper choice of flyer thickness and gap size may allow us to achieve the desired goal. We have examined this concept using the three-dimensional shock physics
ALE code ALEGRA, which includes many different physics options including the required modeling for radiation transport. ${ }^{3}$

\section{BASELINE CONFIGURATION}

As indicated in Fig. 1 , the initial sample configuration consisted of a $50-\mu \mathrm{m}$ flyer, followed by a $30-\mu \mathrm{m}$ gap. The actual target layer was tassumed to be $300 \mu \mathrm{m}$ thick. For all of

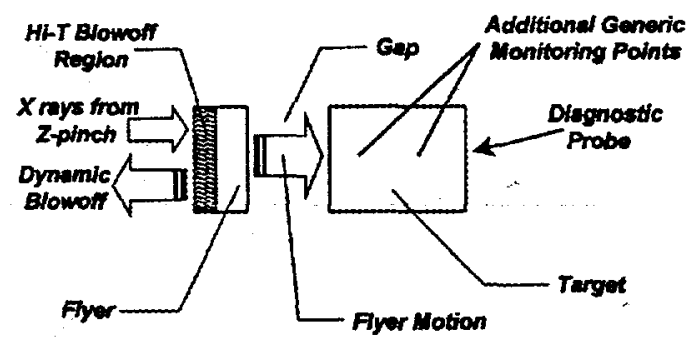

FIGURE 1. Baseline target configuration.

\footnotetext{
- Sandia is a multiprogram laboratory operated by Sandia Corporation, a Lockheed Martin Company, for the United States Department of Energy under Contract DE-AC04-94AL85000.
} 


\section{DISCLAIMER}

This report was prepared as an account of work sponsored by an agency of the United States Government. Neither the United States Government nor any agency thereof, nor any of their employees, make any warranty, express or implied, or assumes any legal liability or responsibility for the accuracy, completeness, or usefulness of any information, apparatus, product, or process disclosed, or represents that its use would not infringe privately owned rights. Reference herein to any specific commercial product, process, or service by trade name, trademark, manufacturer, or otherwise does not necessarily constitute or imply its endorsement, recommendation, or favoring by the United States Government or any agency thereof. The views and opinions of authors expressed herein do not necessarily state or reflect those of the United States Government or any agency thereof. 


\section{DISCLAIMER}

Portions of this document may be illegible in electronic image products. Images are produced from the best available original document. 
these calculations aluminum was used for both the flyer and target. Because ALEGRA cannot transport radiation across true voids, we initially assumed that the gap was filled with gas at a density of $1 \times 10^{-3} \mathrm{~g} / \mathrm{cm}^{3}$. The inclusion of a gas layer also assists the Lagrangian hydrodynamic algorithms in providing a smooth solution when the abrupt closure of the gap occurs. The input energy

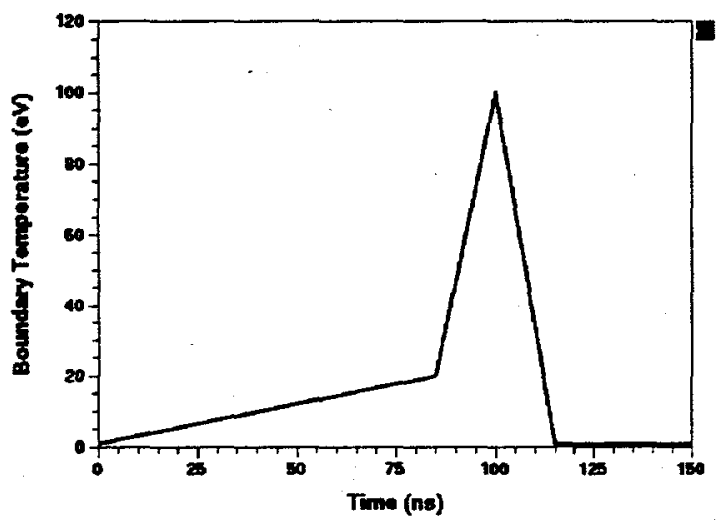

FIGURE 2. Assumed Z-pinch-driven hohlraum temperature.

was specified as a time-dependent blackbody temperature history as shown in Fig. 2 . It is idealized but representative of the output from the $Z$ pinch. To resolve the energy deposition in the flyer, especially that due to the low-temperature early-time portion of the drive, the Lagrangian zone size at the outside of the one-dimensional setup was chosen as $-0.4 \mu \mathrm{m}$; it was allowed to gradually increase through that layer. The $300-\mu \mathrm{m}$-thick target was represented by 100 equal-size zones. Finally, the aluminum was modeled with the SESAME tabular equation of state. ${ }^{4}$

\section{INITIAL CALCULATIONS}

The first full calculations were run as outlined above, including the gas-filled gap, which was represented by one zone. We used the density of that gas to numerically damp the impact of the flyer onto the target layer, and found that it made only minimal differences in the dynamic response of the target. Figure 3 shows a series of pressure histories for Lagrangian points from $-30 \mu \mathrm{m}$ in from the front surface of the target to nearly its rear surface. The 0.4 Mbar "precursor" on the earliest of these traces is due to the initial stages of the impact, which are driven by the low-temperature toe of the temperature history; it is overdriven in the subsequent traces. The single small pulse near 120

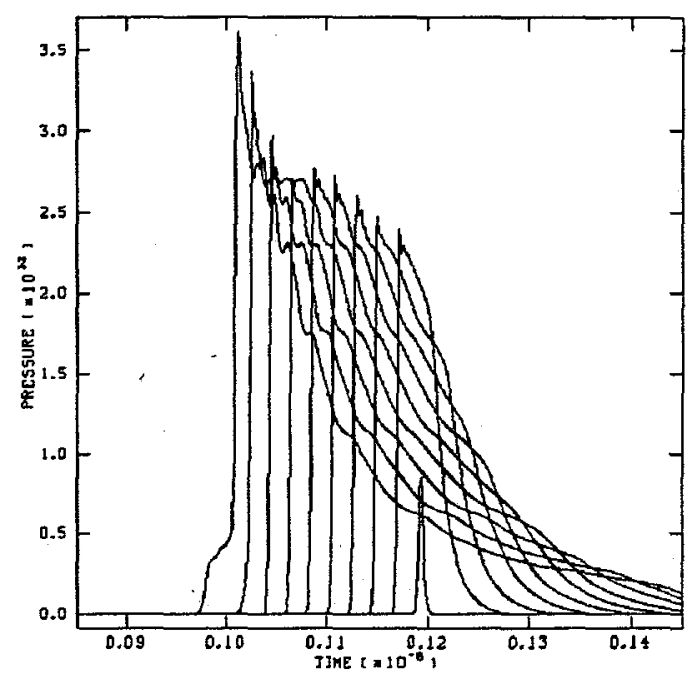

FIGURE 3. Pressure histories in target for $50-\mu \mathrm{m}$ flyer and 30$\mu \mathrm{m}$ gap. [Units: $\mathrm{s}$; dynes $/ \mathrm{cm}^{2}$ ]

ns is for a zone just inside the back surface of the target layer, and clearly shows the influence of the reflection at the free surface. Note that in this and

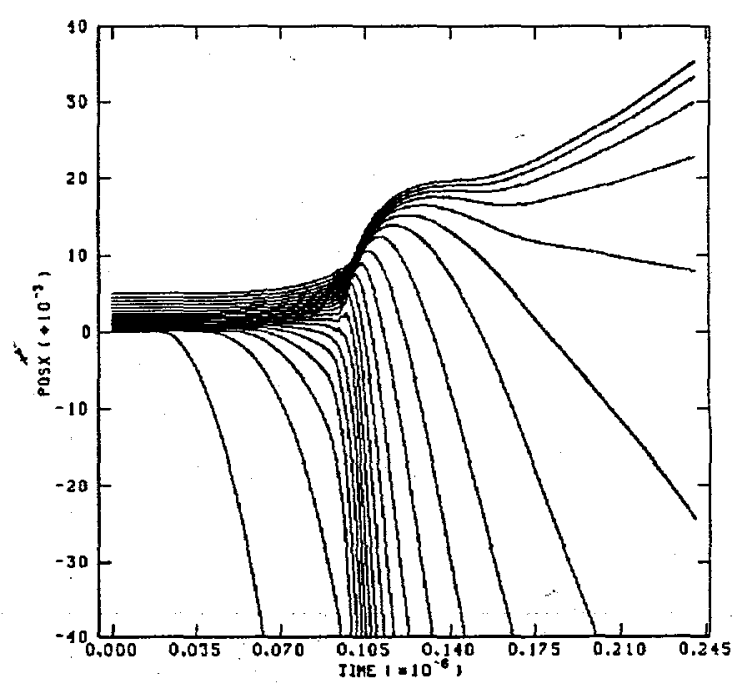

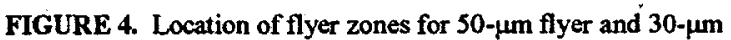
gap. [Units: $s ; \mathrm{cm}$ ]

subsequent plots from ALEGRA, cgs units are used consistently; thus for example, the peak pressures are a little over $3.5 \mathrm{Mbar}$, and the curves are 
centered between 100 and 130 ns. These pressure pulses show significant attenuation as they propagate through the target, suggesting that the flyer is not acting as intended. This can be shown more clearly by looking at the motion of the zones constituting the flyer, as in Fig. 4. Here we plot the physical position of every other zone in the layer as a function of time. We first note the early time ablation of the front surface. It can be seen as early as $35 \mathrm{~ns}$, and is due to the toe of the input temperature history. Although the temperature is not high, it persists for a long time and represents enough energy-most of which is deposited in the outer surface-to yield considerable vaporization. When the main temperature pulse arrives, at between 85 and $115 \mathrm{~ns}$, the rate of blowoff is increased and the large number of zones involved in the process is evident. The remaining portion of the flyer, which is near normal density, is moving toward the target at a velocity that peaks at $\sim 10$ $\mathrm{km} / \mathrm{s}$. But even this material is heated well above its vaporization point and most of it eventually rebounds off the target in a greatly expanded state. Because the flyer provides the only radiation shielding for the target, the latter is subjected to considerable heating, probably too much for a wellcontrolled experiment.

The most important conclusion from these first calculations is that a $50-\mu \mathrm{m}$ flyer is too thin for the assumed radiation drive. It is not thick enough to generate an effective flyer, and it does not provide enough shielding to prevent direct heating of the target.

\section{FURTHER CALCULATIONS}

To improve the situation, subsequent calculations used flyers that were considerably thicker, typically by a factor of two. After many parameter variations, mainly involving the flyer and gap thicknesses, we zeroed in on a 100- $\mu \mathrm{m}$ flyer and a 90- $\mu \mathrm{m}$ gap. Using this latter configuration we find, as shown in Fig. 5, that doubling the flyer thickness does indeed leave an appreciable portion of the layer moving together as a unit at a density that is near normal. As with Fig. 4, we are plotting the positions of every other zone in the layer. All the features of Fig. 4 are present, including the early-time blowoff, the more extensive blowoff coinciding with the peak of the temperature drive at $100 \mathrm{~ns}$, and the later rebound of vaporized material resulting from the interaction with the target. In

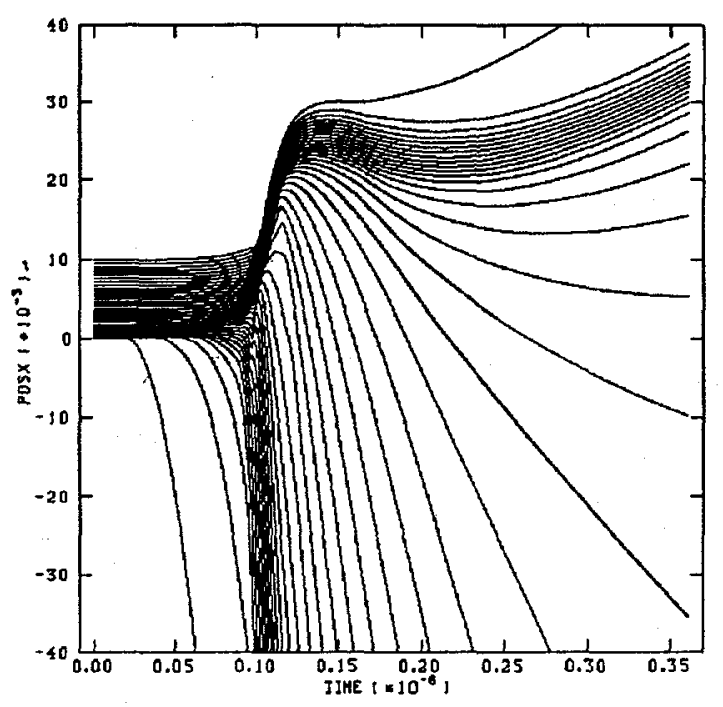

FIGURE 5. Location of flyer zones for $100-\mu \mathrm{m}$ flyer and 90 $\mu \mathrm{m}$ gap. [Units: $\mathrm{s} ; \mathrm{cm}$ ]

this calculation, however, roughly the downstream half of the flyer stays relatively intact, and moves into the gap at an "effective" flyer velocity in

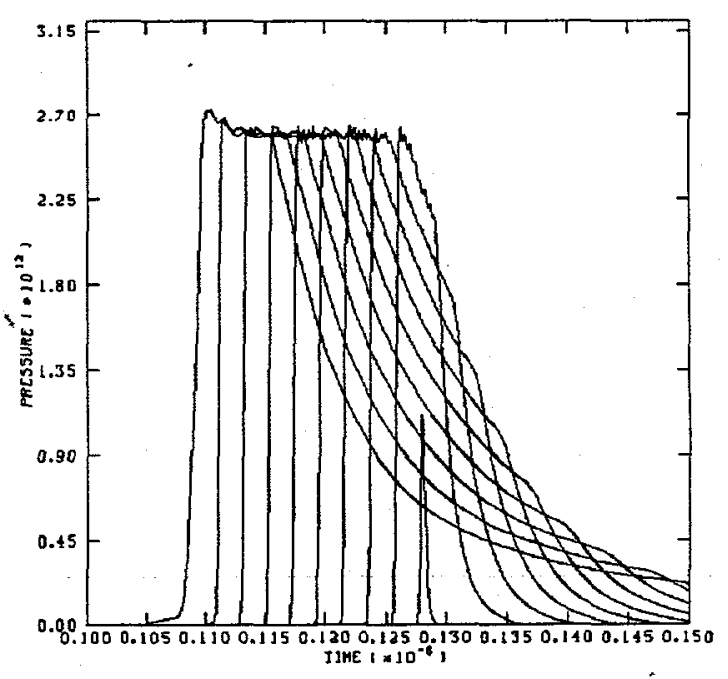

FIGURE 6. Pressure histories in target for $100-\mu \mathrm{m}$ flyer and 90- $\mu \mathrm{m}$ gap. [Units: $s ;$ dynes $/ \mathrm{cm}^{2}$ ]

excess of $10 \mathrm{~km} / \mathrm{s}$, only later rebounding from the target. Although the downstream half of the flyer appears to be at near-normal density, it should be 
remembered that it has been heated, either directly or by shock compression, to temperatures well above the vaporization point of the material. Analogous to Fig. 3, Fig. 6 shows the pressures generated in the target for this configuration. They peak at almost $2.7 \mathrm{Mbar}$, and show little or no attenuation as they move through the target. The contrast with Fig. 3 is evident. Because of the greater flyer thickness, even the precursor seen in

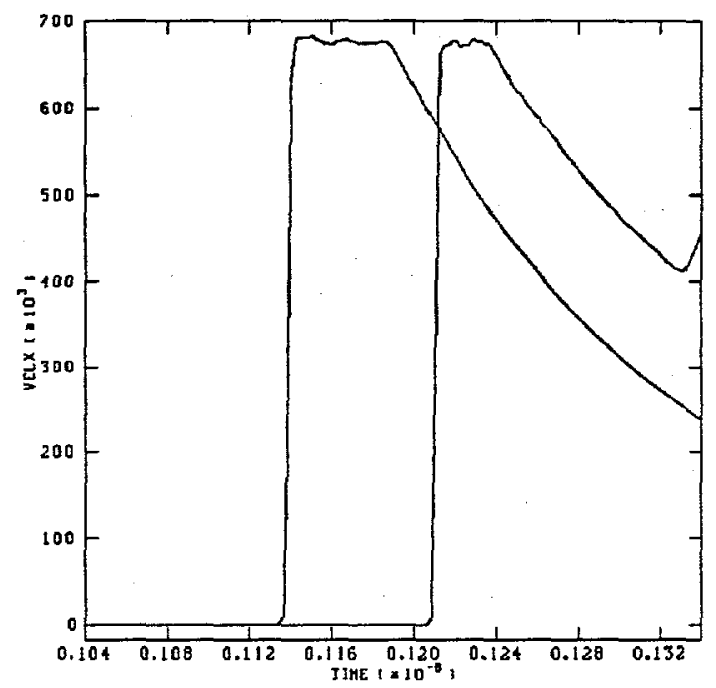

FIGURE 7. Velocity histories for 100 - and $200-\mu \mathrm{m}$ points in target for 100- $\mu \mathrm{m}$ flyer and $90-\mu \mathrm{m}$ gap. [Units: $\mathrm{s} ; \mathrm{cm} / \mathrm{s}$ ]

Fig. 3 is largely missing. Current approaches to obtaining data usually involve particle velocity measurements taken with a VISAR with various target thicknesses using a transparent window of similar shock impedance. As a simulation of what two such velocity profiles might look like, Fig. 7 shows Lagrangian velocity histories for points 100 and $200 \mu \mathrm{m}$ from the front surface of the target layer. They arrive at 114 and $121 \mathrm{~ns}$ respectively, and peak at about $6.8 \mathrm{~km} / \mathrm{s}$, with no change in amplitude between the two locations. The release wave is eating into the pulse width, but at the 100$\mu \mathrm{m}$ position the FWHM pulse width is about $15 \mathrm{~ns}$.

One other point should be mentioned. Even with the $100-\mu \mathrm{m}$ flyer acting as a shield, the radiation source is strong enough that the target is subjected to a small level of direct heating, principally from the main peak of the temperature drive. As a result, it appears that the front of the target is heated well above its melt temperature. This may not be too important since the initial phases of the loading being examined here are all compressive. More importantly, temperatures in the remainder of the target achieve considerably higher values for short times, but this is mainly due to shock heating from the multi-megabar pressures. After the initial response to the compressive loading and its shock heating, the target material relaxes to a state that, according to the calculations, is mostly vaporized. It is thus free to expand at whatever velocities the dynamics dictate.

\section{CONCLUSIONS}

The $x$-ray output from the $Z$ machine offers an important source for obtaining dynamic equation of state measurements under extreme conditions of pressure and temperature. Unfortunately, for conventional materials the direct drive from the $Z$ pinch produces target loads that are not well suited for this task. However, if the target employs two stages, using the direct drive to launch a flyer, and the flyer to provide the dynamic load on the target, we can, in principle, generate a non-attenuating square wave in the target. With an idealized output from the Z-pinch as input, we used the ALEGRA code to conduct a study of the relevant parameters. From the many calculations, we found that the closest approach to the desired target loading was achieved with a $100-\mu \mathrm{m}$ flyer and a gap size of 90 $\mu \mathrm{m}$. These parameters thus provide the best starting point for the relevant experiments. However, these recommendations are limited to aluminum flyers and targets, and are only for experiments that can be tied fairly closely to the assumed Z-pinch output.

\section{REFERENCES}

1. Pereira, N. R, and J. Davis, J. Appl. Phys. 64 (3), R1-R27 (1988).

2. Ryutov, D. D., M. S. Derzon, and M. K. Matzen, The Physics of Fast $Z$ Pinches (SAND98-1632), Sandia National Laboratories, Albuquerque, NM (1998).

3. Summers, R. M., et al., Int. J. Impact Engng. 20, 779-788 (1997).

4. Holian, K. S., ed., T-4 Handbook of Material Properties Data Bases, Vol. 1c: Equations of State (LA-10160-MS), Los Alamos National Laboratory, Los Alamos, NM (1984). 